\title{
Unser Freund, das Genom
}

Erhard Taverna

erhard.taverna[at]saez.ch

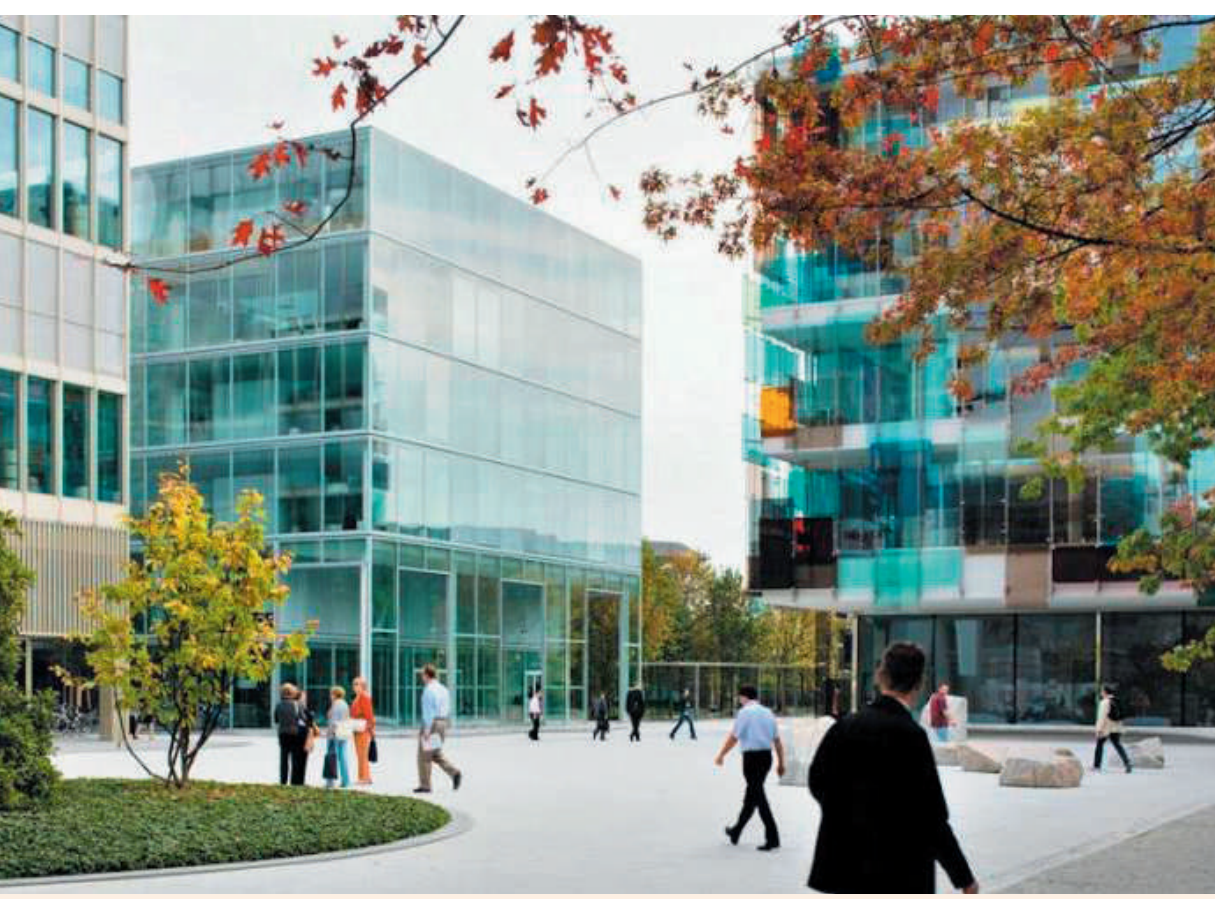

Einige der imponierenden Gebäude des Basler Novartis-Campus, wo Ende Januar die Science Night stattfand.
Wie schimmernde Kristalle wachsen die Büro- und Labortürme aus kunstvollen Gartenanlagen in die einbrechende Nacht. Wer die Eingangskontrolle passiert hat, wandert staunend über die zentrale Campusstrasse des Firmenareals. Nur die Besten haben hier gebaut: Frank Gehry, Moneo Vallés, de Mouro und Fumihiko Maki. Der Konzernsitz von Novartis gehört zum ausgebuchten Programm des Basler Tourismus. Die Gated communitiy plant weitere Bauten und sponsert den Bürgern eine Uferpromenade.

Die eingeladenen Gäste erwartet die erste Science Night des Jahres 2013, Thema: «60 Jahre DoppelHelix. Von Friedrich Miescher in das post-genomi- sche Zeitalter». Hauptredner ist J. Craig Venter, Gründer, Präsident und CEO des gleichnamigen Instituts. 2001 publizierte sein Team die erste Sequenzierung eines kompletten Humangenoms seiner Firma Celera, deren Datenbanken seit 1999 für
Novartis vertraglich einen Zugriff auf neue Informationen über das Genom eröffnen.

Craig Venter war der erste Wissenschaftler, der sein eigenes, diploides Erbgut entschlüsselt im Internet veröffentlichte und 2010 die erste synthetische, computerentworfene Zelle, Mycoplasma mycoides JVC-syn 1.0, konstruierte. Das Ergebnis gilt als Auftakt zur synthetischen Biologie. Craig Venter hält sein spannendes Referat vor einem vollbesetzten Auditorium. Er würdigt seine Vorgänger von Friedrich Miescher über Erwin Schrödinger zu Frederik Sanger, Holley und natürlich Watson und Crick, die 1953 den räumlichen Aufbau der DNS nachwiesen.

\section{Bevor Craig Venter seine eigenen Arbeiten vorstellt, würdigt er die Verdienste schweizerischer Nobelpreisträger.}

Viele andere, wie Kornberg und Arber, schufen die Voraussetzungen zum Erfolg des US-Unternehmens Gentech, das 1977 ein humanes Wachstumshormon und ein Jahr später das Humaninsulin aus gentechnisch modifizierten Organismen produzierte. Bevor Craig Venter seine eigenen Arbeiten vorstellt, würdigt er in seinem Überblick den schweizerischen Anteil an Nobelpreisträgern mit Bezug zur DNS und die führende Position des heutigen Gastgebers. Er vergleicht sein Vorhaben mit der Harnstoffsynthese von Wöhler, der 1828 aus anorganischen Substanzen eine organische Verbindung herstellte, und beschreibt, wie Schritt für Schritt eine Genomsynthese aus vier Chemikalien unter Einsatz eines chemischen Synthesizers gelang. Genom-Transplantationen in Bakterien verwandeln eine Spezies in eine andere, synthetische Oligonukleotide werden zu Bakteriophagen, Mäuse-Mitochondrien nach digitalen Bauplänen realisiert. Der lineare DNS-Code wird konsequent in einen digitalen Code übersetzt: «Life is a DNA-software-system». Das postgenomische Zeitalter ist eines der Synthese neuer Lebewesen. Venter zitiert den amerikanischen Physiker und Nobelpreisträger Richard Feynman: «What I cannot build, I cannot understand.» Seine Labors in Kalifornien programmieren Meeresalgen für die Ernährung und Energieversorgung der nächsten Milliarde Bewohner. Pioniere haben Visionen, zum Beispiel die biologische Teleportation von DNS-Sequenzen als elektromagnetische Welle, etwa vom Mars zur Erde oder vom Pharmahersteller in die Wohnstube, wo 
ein Home-vaccine-module dank dem Digital-biologicalconverter den massgeschneiderten Grippeimpfstoff ins Haus liefert.

Dem konzentrierten Referat folgt ein Podiumsgespräch mit Susan M. Gasser, der Direktorin des Friedrich Miescher Instituts (FMI) für biomedizinische Forschung, und Rino Rappuoli, dem Leiter der Impfstoff-Forschung von Novartis. Basel versteht sich als Epizentrum des europäischen BioValley. $\mathrm{Zu}$ den
Vortrag in weiteren 60 Jahren folgen. Wohin führt der eingeschlagene Weg? Venter und seine Leute sind das Produkt eines Wettlaufs mit dem HumanGenom-Projekt. Gewaltige Summen fliessen derzeit aus der europäischen Flagship-Initiative in Prestigeprojekte wie das Human-Brain-Projekt in Lausanne oder das IT Future of Medicine des Max-Planck-Instituts, das ein Referenzmodell riesiger Mengen an persönlichen Daten vom Genom, Proteom, Metabolom

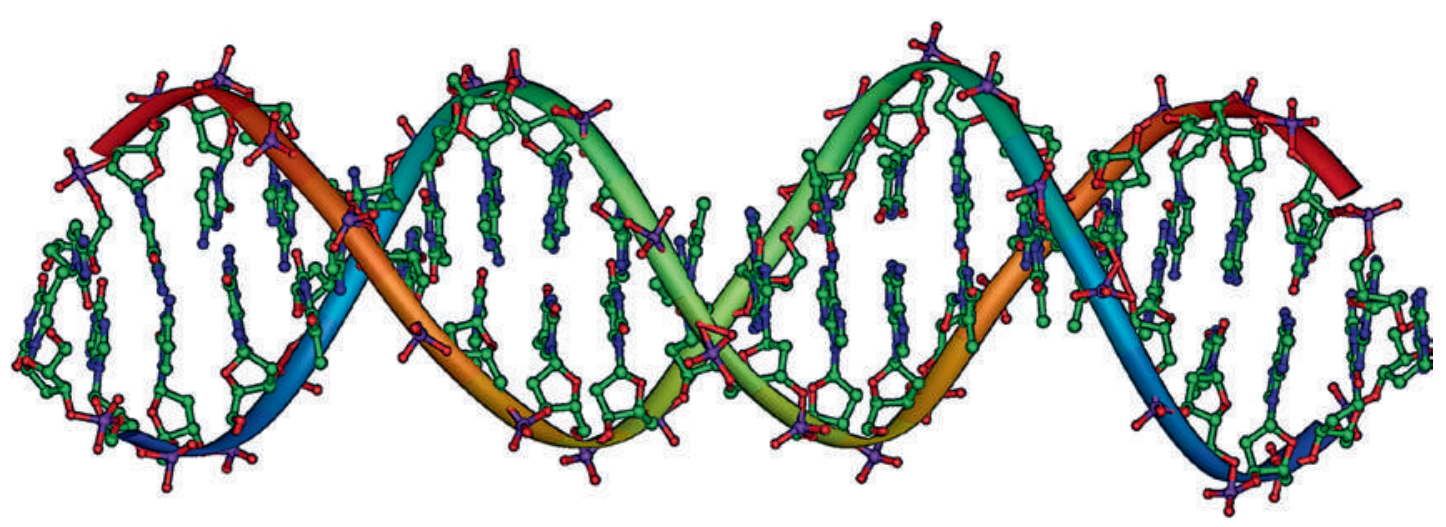

Bild Doppelhelix: Created by Michael Ströck/Commons from en.wikipedia.org

Forschungsschwerpunkten gehört die reverse Vakzinologie, eine Technik zur Entwicklung neuer Impfstoffe mittels Genomsequenzierung von krankheitsverursachenden Erregern. Ein erster Erfolg war der Impfstoff gegen das Meningokokken-Bakterium der Serogruppe B. Novartis arbeitet eng mit dem FMI zusammen, das auf dem Gebiet der Neurobiologie, Tumorbiologie, Pflanzengenetik und Epigenetik forscht und ausbildet. bis zum Mikrobiom entwickelt. Vom CERN bis zur ETH Zürich sind alle namhaften Institute als Partner beteiligt. Segen oder Fluch? Ein alter Wandgraffito brachte es ironisch auf den Punkt: «Life is Xerox, you are just a copy.»

Der Biologe Adolf Portmann, wie Miescher ein bekannter Basler, zweifelte und hoffte: «Ich bin überzeugt, das heute dominierende Erkenntnisstreben werde zwangsläufig ein Werkzeug des Zerstörens

\section{Gerne würde man dem nächsten Vortrag in weiteren 60 Jahren folgen. Wohin führt der eingeschlagene Weg?}

In der imposanten Arbeitslandschaft am Rhein wird auf Weltklasseniveau gearbeitet, daran lässt der brillante Parcours der Spitzenkräfte keinen Zweifel. Auf dem Rückweg zur Glasschleuse am Eingang mischen sich Faszination mit Skepsis, Bewunderung mit Einwänden. Gerne würde man dem nächsten bleiben, mag der einzelne Forscher dagegen ankämpfen oder nicht; dass aber in dem Glauben an einen tiefsten Geheimnisgrund auch unseres eigenen Wesens heilende Möglichkeiten verborgen sind.» (An den Grenzen des Wissens, 1974) 